\title{
Author/Subject Index Vol. 7, No. 3-4, 1997
}

\section{Aiyar, J. 135}

Cahalan, M.D. 133,219,229 Chandy,K.G. 135 Chang, M.C. 159 Chung, I. 159 DeCoursey, T.E. 172 Dolmetsch, R.E. 203 Fanger, CM. 203 Garber, S.S. 229 Grissmer, S. 179 Gulbins,E. 148

Gutman, G.A. 135 Hoth,M. 203 Jäger,H. 179 Lang,F. 148

Lepple-Wienhues, A. 133, 219 Lewis, R.S. 203 Schlichter, L.C. 159 Strong, M. 135 Szabò, I. 148 Verheugen, J.A.H. 188 Zweifach, A. 203

Anion selectivity 229 Apamin 179 Apo-1 148 Apoptosis 148 Ca2+signaling 188 Ca2+activated potassium channel

188 Calcium oscillations 203 - signaling 203 Calmodulin 159 Capacitative calcium entry 203,

219 Cell volume regulation 229 Cell-attached patch-clamp 188 Ceramide 148

Charybdotoxin 179, 188 Chloride channel 229 Delayed rectifier 172 Diacylglycerol 159

Electrophysiology 179

Fas 148

fura-2 203

Gene expression 203

Immunosuppression 159

Ion channel 172

permeation 172,219 K+channel $172 \mathrm{~K}$-channel block 159

phosphorylation $159 \mathrm{Kvl} .3148$

Kv3.1 172 Lymphocyte 148, 172

- $\quad$ ion channel 219

Lymphoproliferation 172

Membrane potential 188

Mitochondria 203

Mutants 203

NGK2 172

Ny statin 159

Patch-clamp 203

PKA 159

PKC 159

Proliferation 188

Scyllatoxin 179

SK channels 179

Small calcium-activated potassium

channels 179 src-like tyrosine kinase 148 Store-operated calcium channel 
219 T-cell activation 159 T lymphocyte(s) 188 - proliferation 159 Thapsigargin 203 Type/ 172 Voltage-gated potassium channel

148

\section{KAIUiER}

E-Mail karger@karger.ch Fax+ 41613061234 http:// www. karger. ch

(C) 1997 S. KargerAG, Basel 